http://jmscr.igmpublication.org/home/ ISSN (e)-2347-176x ISSN (p) 2455-0450 crossref DOI: https://dx.doi.org/10.18535/jmscr/v9i1.02

\title{
Study of Branching Pattern of Left Coronary Artery in South Indian Population
}

\author{
Author
}

\section{Dr C. P. Anbarasi}

Senior Assistant Professor, Department of Anatomy, Government Thiruvannamalai Medical College,

Tamil Nadu, India

Corresponding Author

Dr C. P. Anbarasi

\begin{abstract}
Background: Coronary artery disease is one of the leading cause of mortality in developing countries like India. The increasing use of diagnostic techniques and therapeutic interventions need a thorough knowledge of the normal branching pattern of coronary arteries and its variation. Most of the area of the Heart is supplied by the Left coronary artery and this artery presents wide variation in the branching pattern. Since this is the most commonly affected artery and first artery to show blockage, this study was conducted.
\end{abstract}

Materials and Methods: 50 Heart specimens were examined in the Institute of Anatomy, Madurai medical college, Madurai.

Results: Left coronary artery Bifurcation (70\%), Trifurcation (26\%) and Quadrification (4\%). SA Nodal artery arises from LCA (22\%). PIVA arises from LCA (10\%)

Conclusion: Knowledge of variations in the branching pattern is useful for cardiologist and cardiothoracic surgeon for angiographic interpretation, stenting procedures and surgical myocardial revascularization.

Keywords: Left coronary artery, Bifurcation, Trifurcation, Quadrification, Sino atrial nodal artery, Posterior interventricular artery.

\section{Introduction}

Cardiovascular system is the first major system to function in embryo. Primordial heart and vascular system appear in the middle of 3rd week of embryonic life, but the heart starts function at the beginning of 4 th week.

Heart is supplied by 2 coronary arteries right and left. Each coronary artery is vasa vasorum of ascending aorta because heart is developed from fusion of two endothelial heart tubes which represent the central aorta. Coronary circulation is unique in that the heart is responsible for generating the arterial pressure that is required to perform the systemic circulation and yet the same time has its own perfusion impeded during the systolic portion of cardiac cycle. The prevalence rate of coronary heart disease in India is $9-10 \%$ in Urban population and $4-6 \%$ in rural population. The left coronary artery when compared to the right is larger in calibre and supplies a greater volume of myocardium that includes almost the whole of the left ventricle and atrium. It also 
supplies most of the Interventricular septum. It arises from left posterior aortic sinus, sometimes the ostium may be double with the anterior Interventricular and circumflex arteries arise directly from the sinus. On reaching the coronary sulcus the left coronary artery divides into two main rami. They are Anterior Interventricular artery and Circumflex artery. Median artery is one that takes origin in the vertex of the angle formed by the two terminal branches of LCA or in the first few millimetres, possesses a substantial calibre and passing half way down the free wall of left ventricle.

\section{Materials \& Methods}

About 50 adult human hearts were dissected and studied. The study was conducted over a period of 2 years from 2013-2015. Formalin fixed heart specimens with intact coronary arteries were taken. Sex of the specimens were not known. Hearts which are lacerated, grossly mutilated and decomposed were excluded. Ethical clearance was obtained from the Institutional Ethical Committee. Steps of Dissection: The heart specimens were preserved in $10 \%$ formalin solution. They were tagged numerically. The visceral pericardium was stripped off and fat was removed from the coronary sulcus. The left coronary artery was traced from its origin till its termination. All the branches were dissected and variations recorded. Statistical analysis was done.

\section{Results}

In this current study, the left coronary artery was seen bifurcating into two main branches in thirty five specimens $-70 \%$ (as shown in Fig-1) trifurcating in thirteen specimens $-26 \%$ as shown in Fig-2) and Quadrification in 2 specimens -4\% (as shown in Fig-3). Among the thirteen trifurcating specimens, in four specimens the diagonal artery which was not seen arising from the anterior Interventricular artery was seen at the junction between its two branches and in nine specimens, diagonal artery was seen arising from anterior Interventricular artery and an additional branch was seen at the junction called the "Median artery".

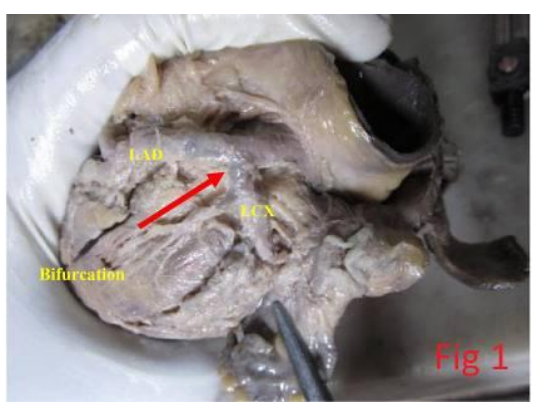

Fig 1: Bifurcation

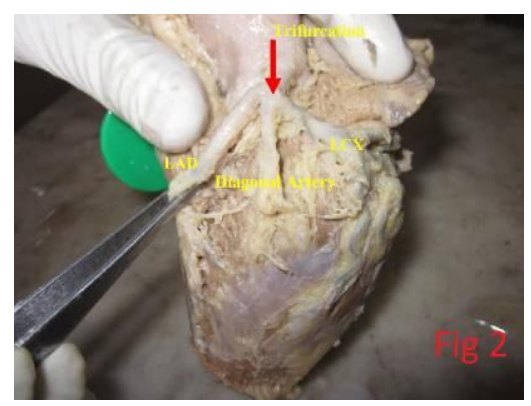

Fig 2: Trifurcation

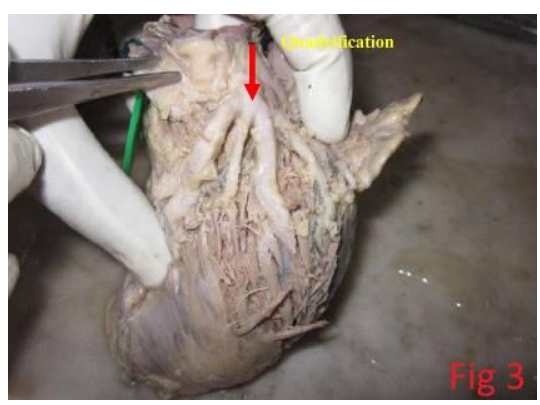

Fig 3: Quadrification

\section{Anterior Interventricular Artery}

The Anterior Interventricular artery and its branches left conus artery, diagonal artery, atrial and ventricular rami were seen in all fifty specimens. The nine trifurcating specimens showed a branch of median artery (as shown in Fig-4) at the junction of its two main branches along with the diagonal artery arising separately from anterior Interventricular artery.

Myocardial bridges were seen over anterior interventricular artery in nineteen specimens (as shown in Fig-5). 


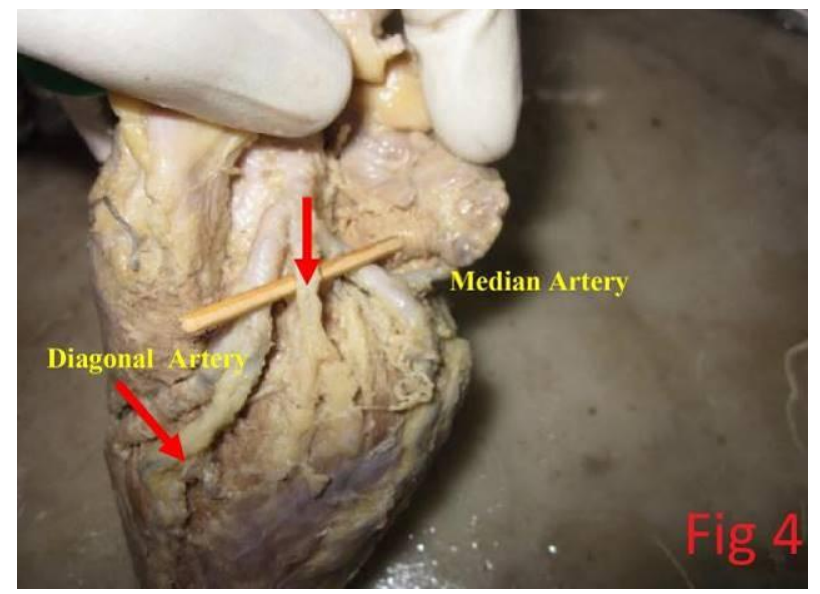

Fig 4: Median Artery

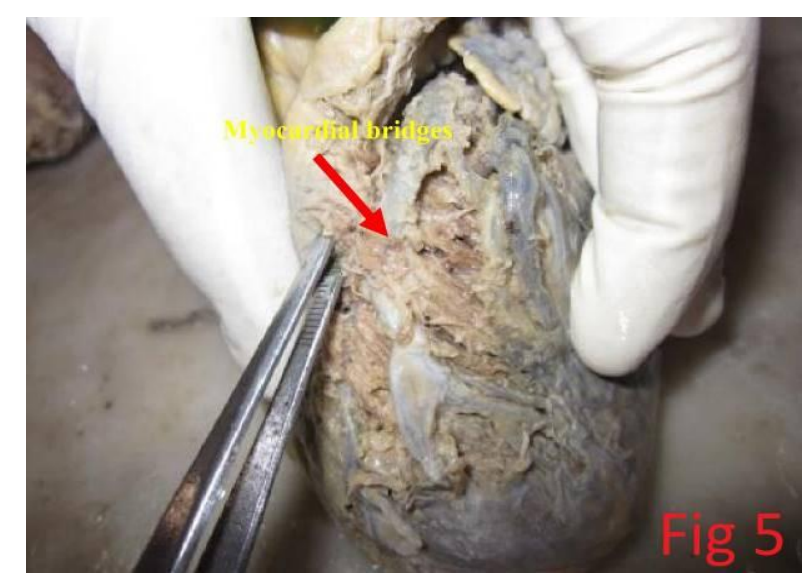

Fig 5: Myocardial bridges

\section{Left Circumflex Artery}

The left circumflex artery and its branches left marginal artery, posterior interventricular artery and Atrioventricular nodal artery were present in all the specimens

The Sino atrial artery which is usually a branch from right coronary artery was seen arising as first branch of left circumflex artery in eleven specimens-22\% (as shown in Fig-6).

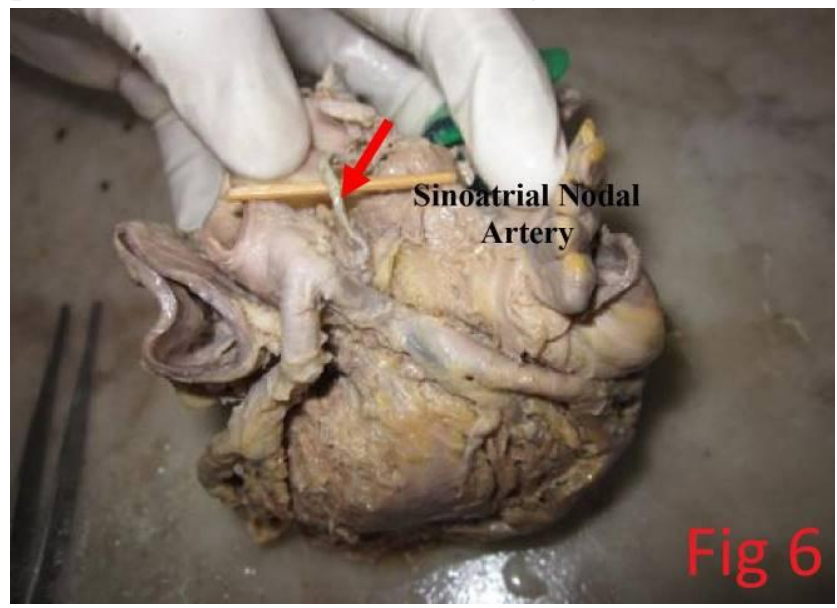

Fig 6: Sinoatrial Nodal Artery
The posterior interventricular artery determining coronary dominance was seen arising from left circumflex artery in 5 specimens (10\%) (as shown in Fig-7). Double posterior interventricular arteries seen in specimens $(23,33)$ (as shown in Fig-8).

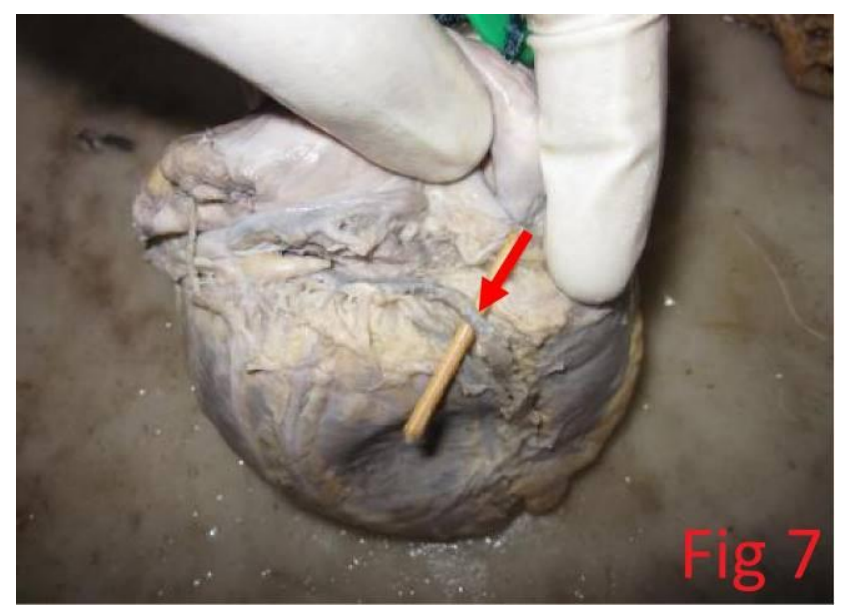

Fig 7: PIVA from LCX

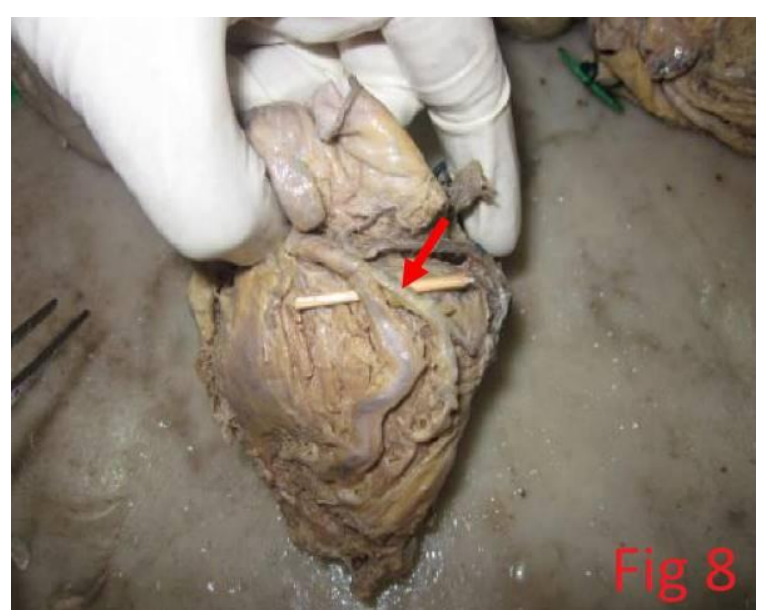

Fig 8: Double PIVA

\section{Discussion}

The first evidence of coronary vessel development begins during third week of Intra uterine life. The stages involved in the development of coronary arteries are vasculogenesis, angiogenesis, arteriogenesis and remodelling. Due to this complexity in the development of coronary arteries, anomalies and variations are common ${ }^{(1)}$. Variations in the branching pattern of main trunk have important clinical manifestations.

The first rule of atherosclerosis states that it is prone at branching points ${ }^{(2)}$. Trifurcation has a protective role against myocardial ischaemia but it 
may cause technical difficulties during catheterisation and a source of complication ${ }^{(3)}$. A large ramus supplies a wide area in the angle between LAD and LCX. This can protect against ventricular fibrillation by providing electrical stability if the LAD has acute occlusion.
Left main impedence is less in trifurcation. This is due to the fact, left main empties into 3 distinct ostia rather than 2 . The combined cross sectional area of these 3 ostia confers a hydrodynamic $\operatorname{advantage}^{(2)}$.

\section{Results of previous studies-A Review of literature}

Table I- Division of main trunk of LCA

\begin{tabular}{|l|l|l|}
\hline S.no & Author & Branching pattern of LCA \\
\hline 1 & Baptista et al(1991) & Bifurcation(54.7),Trifurcation(38.7), Quadrification(6.7) \\
\hline 2 & Reig J et al(2004) & Bifurcation(62\%), Trifurcation(38\%) \\
\hline 3 & Das Hirak(2005) & Bifurcation(60\%), Trifurcation(35\%), Quadrification (5\%) \\
\hline 4 & Lujinovic et al(2005) & Bifurcation (65\%),Trifurcation (35\%) \\
\hline 5 & Ballesteros et al (2008) & Bifurcation (52\%),Trifurcation (42\%), Quadrification (5.8\%) \\
\hline 6 & Gaurav Agnihotri(2013) & Bifurcation(66\%),Trifurcation(30\%), Quadrifiaction(4\%) \\
\hline 7 & Dharmendra(2013) & Bifurcation (58\%),Trifurcation(35.5\%)Quadrification(6.5\%) \\
\hline 8 & Present study(2015) & Bifurcation(70\%),Trifurcation(26\%), Quadrification(4\%) \\
\hline
\end{tabular}

The third terminal branch of main trunk of LCA is marked as median artery. This branch and its anastomosis represents an important pattern of the collateral circulation under conditions of coronary insufficiency ${ }^{(4)}$.

Presence of several long and deep myocardial bridges can be the anatomical basis that facilitates the origin of clinical events such as angina, arrhythmia or even sudden death which originate from situations of high demand on heart function such as stress or exercise ${ }^{(5)}$.It can be diagnosed by coronary angiography where a typical milking effect and step down-step up phenomenon induced by the systolic compression of tunnelled segment may be seen.

The distribution of SA nodal arteries allow to understand the possible ischaemic cause of the sinusal nodal syndrome and permits the surgeon a safe approach to the cardiac diseases ${ }^{(6)}$.

Table II - Origin of Sino atrial Nodal artery

\begin{tabular}{|l|c|c|c|c|c|}
\hline S.no & Author & Year & RCA (\%) & LCA(\%) & BOTH(\%) \\
\hline 1 & Baroldi Scomazzoni & 1956 & 51 & 41 & 8 \\
\hline 2 & James & 1961 & 54 & 42 & 4 \\
\hline 3 & Caetano\& lopes & 1995 & 58 & 42 & 0 \\
\hline 4 & Kalpana & 2003 & 56 & 35 & 9 \\
\hline 5 & Padmashree et al & 2014 & 80 & 10 & 10 \\
\hline 6 & Present study & 2015 & 78 & 22 & 0 \\
\hline
\end{tabular}

PIVA determines the coronary dominance. The blood supply of the inferior myocardium depends on the dominance. Hence knowledge of these variations play an important role in treating inferior wall infarcts. Left dominance was found to have significantly higher mortality than right dominance and mixed types ${ }^{(7)}$

Table III- Comparison of the origin of posterior interventricular artery

\begin{tabular}{|l|c|c|c|c|}
\hline S no & Authors & RCA\% & LCA\% & BOTH\% \\
\hline 1 & Kalpana (2003) & 89 & 11 & 0 \\
\hline 2 & Hirak Das et al (2010) & 70 & 18.5 & 11.43 \\
\hline 3 & Ballesteros (2011) & 76 & 6.8 & 17.2 \\
\hline 4 & Nordon D G(2012) & 88 & 8 & 4 \\
\hline 5 & Jyoti P.Kulkarni(2013) & 90 & 10 & 0 \\
\hline 6 & Padmashree et al(2014) & 89 & 11 & 0 \\
\hline 7 & Present study(2015) & 90 & 10 & 0 \\
\hline
\end{tabular}




\section{Conclusion}

A detailed knowledge of all these variation is crucial for the interpretation of coronary angiogram, implementation of stenting procedures and surgical revascularization of myocardium. Left main trifurcating lesion is more complex and generally treated with bypass surgery. Trifurcation stenting carries a high rate of adverse events and reserved for patients who refuse surgery.

\section{Acknowledgements}

I wish to express my sincere thanks to Dr. Vidhulatha, Dr. Pushpakala and Dr . Latha, Assistant Professors, Institute of Anatomy, Madurai Medical College for their encouragement and help extended during this study.

\section{References}

1. Sadler TW. Langman's Medical Embryology. Cardiovascular system.11 th ed. London: Lippincott, Williams and Wilkins;2009;183-90

2. Mamatha and Chaitanya Sridhar: Anomalous Branching Pattern of coronary vessels. CIB Tech Journal of surgery SSN:2319-3875,2014 VOL.3(2),PP 17-2

3. Tomar $\mathrm{S}$ et al: Normal and variant anatomy of Left coronary Artery: 64-slice Multi Detector Computed Tomography (MDCT).Coronary Angiographic Depiction in North Indian population IJSRP, volume 3, issue 8, August 2013.

4. Padmashree Chougule et al, Variations in Branching pattern of coronary arteries.IJSR,VOL3 (8),pg 270-273

5. Ballesteros and Ramirez: Morphological expression of the left coronary artery: a direct anatomical study. Folia Morphol 2008, vol 67,No.2, pp 135-142

6. Caetano \& Lopes (1995): Critical analysis of the clinical and surgical importance of variations in the origin of sino atrial nodal artery of the human heart. Rev Assoc Brass 41(2):94-102
7. Hirak Das et al: A study of coronary dominance in the population of Assam. J. Anat. Soc. India 59(2) 187-191(2010)

8. Baptista et al:Types of division of the left coronary artery and ramus diagnosis of the human heart. Jap Heart J,1991,32:323-335

9. Reig et al: Main trunk of the left coronary coronary artery: Anatomic study of the parameters of clinical interest. clinical anatomy 2004,17:6-13.

10. Lujinovic A et al, Bosn J Basic Med Sci 2005;5:69-73.

11. Gaurav Agnihotri, 2013: Branching pattern of Left coronary artery. Anatomy Journal of Africa vol 2,Issue 2.

12. Dharmendra et al (2013), clinically significant anatomical variations of the left coronary artery in human cadaveric hearts. Int J Cur Res Rev, vol 5(12)pg 39-43.

13. Baroldi and Scomazzoni G (1965) Coronary circulation in the normal and pathologic heart. Armed Forces Institute of Pathology; Washington D.C.pp 1-37.

14. James TN (1961).Anatomy of the coronary arteries. New York, pp 12-150.

15. Kalpana R.2003. A study of principal branches of coronary arteries in humans. J Anat soc. India. 52 (2): 137-40.

16. Nordon D G (2012): Variations in the anatomy of the coronary arteries. $J$ Morphol Sci, 29(3), 178-181.

17. Jyoti P. Kulkarni (2012): A study on angiographic anatomy of left main coronary artery system. IOSR Journal of Dental and Medical Sciences,3(2):5-7.
Abbreviations
LCA - Left coronary artery.
LCX - Left circumflex artery.
SA - Sino atrial.
RCA - Right coronary artery.
PIVA - Posterior Inter Ventricular Artery 